\title{
FÉCULA DE BATATA COMO ADJUNTO DE MALTE NA FABRICAÇÃO DE CERVEJA
}

\author{
DOMÊNICA ANDRADE DE MATOS* \\ IRATAN JORGE DOS SANTOS** \\ JANE SELIA REIS COIMBRA*** \\ PAULO HENRIQUE ALVES DA SILVA***
}

\begin{abstract}
O objetivo deste trabalho foi comparar o rendimento da mosturação, usando amido de milho e fécula de batata como adjuntos de malte para a produção de cerveja com melhor qualidade final. Esse parâmetro foi avaliado, principalmente, em relação ao rendimento de produção de açúcar no mosto primário, no mosto misto e no filtrado. No processamento da cerveja, a brassagem foi realizada pelo processo de duas massas. A hidrólise do amido de milho disponibilizou maior quantidade de açúcar solúvel para o meio comparado com a fécula de batata. Isto pode ser devido à constituição química diferenciada das duas fontes de amido em termos de amilose e amilopectina. Deve-se considerar ainda que a batata apresenta baixo teor de proteínas e óleo, o que diminui o risco de turvação, melhora a estabilidade da espuma da cerveja e reduz gastos com o uso de estabilizantes. A estabilidade física da cerveja proporciona maior tolerância ao resfriamento e maior vida de prateleira.
\end{abstract}

PALAVRAS-CHAVES: AMIDO DE MILHO; FÉCULA DE BATATA; MOSTURAÇÃO; CERVEJA.

\section{INTRODUÇÃO}

No Brasil, o Ministério da Agricultura é o órgão responsável pelo estabelecimento de normas de identidade e qualidade para bebidas alcoólicas e não-alcoólicas. De acordo com o decreto 2314 de 1997, desse Ministério, a cerveja é a bebida obtida pela fermentação do malte de cevada e água potável por ação da levedura, com adição de lúpulo.

* $\quad$ Bacharel em Química, Departamento de Química, Universidade Federal de Viçosa (UFV), Viçosa, MG (e-mail: domenicamatos@yahoo.com.br).

** Doutorando em Ciência e Tecnologia de Alimentos, Departamento de Tecnologia de Alimentos, UFV, Viçosa, MG.

*** Professores do Departamento de Tecnologia de Alimentos, UFV, Viçosa, MG. 
Parte do malte de cevada pode ser substituída por cereais malteados ou não e por carboidratos (ARAÚJO, 2000). As fontes de carboidratos utilizadas em substituição ao malte são chamadas "adjuntos". Esses são adicionados ao malte de cevada, em proporções balanceadas, como fonte secundária de carboidratos para o processo de fermentação, podendo assim reduzir parcialmente os custos de produção (COSTA JÚNIOR, 1996).

Justifica-se o crescente interesse pela utilização de amido na produção de álcool por tratar-se de matéria-prima renovável e globalmente disponível em grandes quantidades. A fermentação alcoólica por leveduras imobilizadas tem sido estudada nos últimos anos, quase sempre utilizando açúcar na forma de melaço ou amido puro como principal substrato. Há poucos trabalhos usando matéria-prima no seu estado natural como a batata-doce seca, que é substrato adequado à fermentação alcoólica por leveduras e apresenta elevado conteúdo de matéria sólida (YU et al., 1996; TSCHOPE, 2001; NAKANO, 2000).

Cereais não-malteados, raízes e tubérculos, são usados como complementos amiláceos, uma vez que o elevado poder amilolítico do malte de cevada permite a incorporação de $50 \%$ de amido de coadjuvantes. Para que ocorra perfeita hidrólise do amido dos complementos adicionados é necessário gelatinizá-los, previamente, para expô-los ao ataque das enzimas do malte (PERPETE e COLLIN, 2000).

De acordo com VENTURINI FILHO (1993), o poder amilolítico do malte determina a quantidade de adjunto a ser utilizado na formulação da cerveja. Qualquer planta que contenha amido, teoricamente, pode ser utilizada como complemento. No caso dos cereais, que não devem ser malteados, é preciso considerar, principalmente, o valor econômico, a disponibilidade e o teor de amido (KUIPER et al., 2001).

Os complementos mais comuns são o milho, o arroz, o trigo e a própria cevada não-malteada, além de féculas de batata ou de mandioca (polvilho doce). São empregados sob diferentes formas físicas, como grão desgerminado e farinhas ou amido, dependendo da relação custo-teor de amido. O amido purificado sempre terá custo mais elevado que o da farinha e o do grão desgerminado para o mesmo cereal. No Brasil, entre os cereais citados, são descartados de início o trigo e a cevada por serem quase totalmente importados. O sorgo, proveniente de variedades gramíferas, seria substituto razoável. O milho, mesmo na forma de canjica, tem sido substituído por tratar-se de cereal amplamente empregado na 
alimentação humana e animal. As indústrias cervejeiras têm dado preferência à quirera de arroz como complemento por se enquadrar nas condições exigidas. Constituída de grãos de arroz quebrados, com um terço da metade do comprimento do grão, está mais disponível, além de apresentar menor valor comercial e alto teor de amido (AMBEV, 2005; VENTURINI FILHO, 1993).

Os carboidratos prontamente fermentáveis, como açúcar de cana, xarope de glicose, açúcar invertido e caramelo (também utilizado como corante) podem ser utilizados como complementos do malte. Não necessitam de sacarificação, sendo convertidos quase completamente em álcool na fermentação. Maltes com teor de proteína muito elevados exigem o uso de complementos nas formas mais purificadas para reduzir o risco de turvação da cerveja. Outra dificuldade com o malte e, principalmente, com os complementos do malte envolve seu teor de gordura. A gordura e outros lipídios interferem na estabilidade da espuma da cerveja, portanto quanto menor o teor dessas substâncias nas matérias-primas melhor será a estabilidade da espuma e menor a necessidade do uso de estabilizantes (HORNSEY, 2002).

A fécula de batata, amido pouco utilizado no Brasil, apresenta potencial como complemento devido ao seu baixo teor de proteínas e de óleo e elevado teor de amido (FRANCO, 2002). Além disso, não é largamente empregada em nível industrial, ao contrário do milho que é amplamente utilizado na indústria de alimentos. O custo do processo poderia ser reduzido pela grande disponibilidade da batata no Brasil, principalmente, quando proveniente de regiões com relevo acidentado. Nessas regiões não há colheita mecanizada, ocorrendo sobra de batata nos campos. A batata oferece vantagem sobre o arroz pela maior rapidez na extração de amido.

Segundo PERPETE e COLLIN (2000) as cervejarias regionais têm utilizado adjuntos pouco convencionais, tais como a batata, mandioca, triticale, aveia e centeio. No Japão são fabricados o awamori e o uri mediante fermentação de batatas-doces (Ipomoea batatas) (VARNAM e SUTHERLAND, 1994).

O processo industrial de produção de cerveja envolve as etapas de moagem do malte, mosturação, filtração do mosto, fervura, resfriamento e aeração do mosto, fermentação, maturação, clarificação, carbonatação, engarrafamento e pasteurização (REINOLD, 2001; MULLER, 2000; LEWIS e YOUNG, 1995; LEE, 1996). 
O objetivo deste trabalho foi comparar o rendimento da mosturação, usando amido de milho e fécula de batata como adjuntos de malte para a produção de cerveja com melhor qualidade final. Esse parâmetro foi avaliado, principalmente, em relação ao rendimento de produção de açúcar no mosto primário, no mosto misto e no filtrado.

\section{MATERIAL E MÉTODOS}

\subsection{MATERIAL}

Foram utilizados malte francês com 3 a 5,5 \% de umidade, lúpulo em "pellets", água potável e amido de milho e fécula de batata como adjuntos do malte.

\subsection{MÉTODOS}

\subsubsection{Mosturação}

O mosto foi produzido com malte moído de forma a expor o endosperma. $\mathrm{Na}$ fase de mosturação utilizou-se evaporador aberto com circulação de vapor, provido de agitação (pá do tipo âncora, 65 rpm) e água no total de 60 litros de mosto para $12 \mathrm{~kg}$ de malte. O processo empregado foi o de duas massas de temperatura ascendente. A Figura 1 apresenta a relação entre o tempo e a temperatura na mosturação pelo processo de duas massas.

No preparo do mosto, a temperatura inicial de $50^{\circ} \mathrm{C}$ foi elevada até $68-$ $70^{\circ} \mathrm{C}$ durante 30 minutos na proporção de $1^{\circ} \mathrm{C} /$ minuto. $\mathrm{O}$ sistema permaneceu nessa temperatura de hidrólise por 30 minutos. Elevou-se a temperatura para $80^{\circ} \mathrm{C}$, visando inibir posteriores transformações enzimáticas. $O$ mosto foi filtrado em tecidos de algodão limpos e esterilizados para separação da torta. Após a separação do mosto, a torta foi lavada uma vez com 40 litros de água potável a $78-80^{\circ} \mathrm{C}$ (para $12 \mathrm{~kg}$ de bagaço, em cada lavagem ). Adicionou-se o adjunto ao mosto, que foi submetido à fervura por 60 a 90 minutos. A proporção do adjunto adicionado em relação ao malte foi de 1 para 4, sendo o tratamento 1: malte + amido de milho e o tratamento 2: malte + fécula de batata.

As Figuras 2 e 3 apresentam os fluxogramas da obtenção de mosto utilizando, respectivamente, amido de milho e fécula de batata como adjuntos. 


\section{FIGURA 1 - RELAÇÃO DE TEMPO E TEMPERATURA PELO PROCESSO DE DUAS MASSAS}

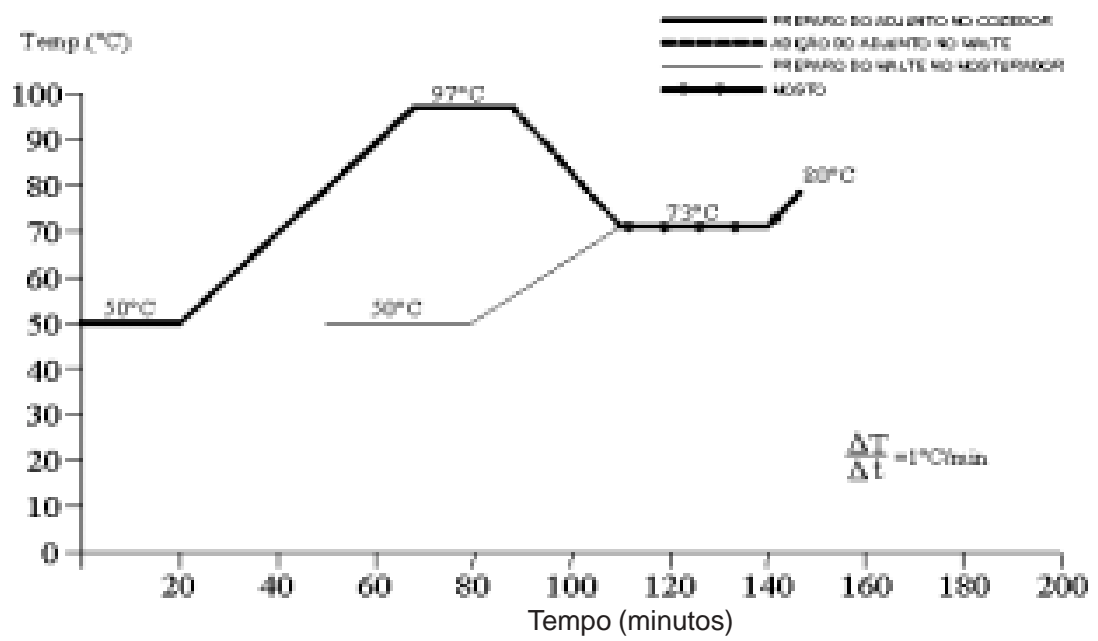

Durante a fervura do mosto foi adicionado lúpulo na forma de "pellets" pelo método das três cargas (início, meio e final da fervura) na proporção de $8 \mathrm{~g}$ para $12,5 \mathrm{~kg}$ de mosto misto (VENTURINI FILHO, 1983). Efetuouse o monitoramento das transformações de degradação do amido pelo teste do iodo (solução aquosa $0,20 \mathrm{~N}$ de iodo).

No final do cozimento foram determinados os teores de açúcar das tortas e dos extratos, os volumes finais dos extratos e as massas das tortas. Efetuou-se a correção do teor de sólidos solúveis no extrato para 12 Brix com água potável. Embora o método de sólidos solúveis não seja específico para determinação de açúcares tem sido, freqüentemente, empregado para estimar o teor de açúcares totais fermentescíveis na área de fermentações. Os experimentos foram conduzidos em recipientes de plástico com capacidade para 70 litros.

O processo de duas massas consiste no uso de dois evaporadores, sendo um para gelatinizar o amido proveniente do adjunto cervejeiro e o outro para a mosturação. Enquanto o adjunto está disponibilizando amido em um evaporador, as enzimas do malte estarão sendo ativadas no outro. Posteriormente, a massa de adjunto é transferida para o mosturador que já contém o malte. 


\section{FIGURA 2 - FLUXOGRAMA DA FABRICAÇÃO DE CERVEJA UTILIZANDO AMIDO DE MILHO COMO ADJUNTO DO MALTE E MOSTURAÇÃO PELO PROCESSO DE DUAS MASSAS}
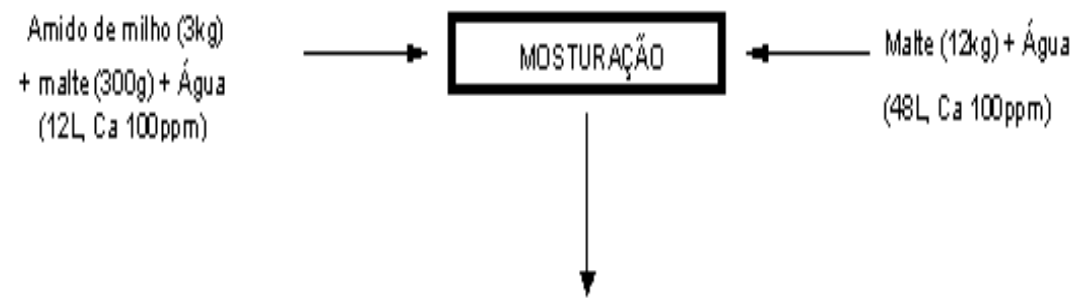

Água(40L, Ca 100ppm)
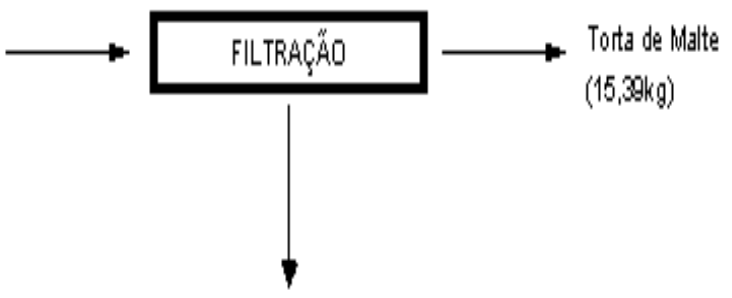

Mosto misto $(43 \mathrm{~kg})$ $(15,30 \mathrm{~kg})$

Lúpulo (8g)
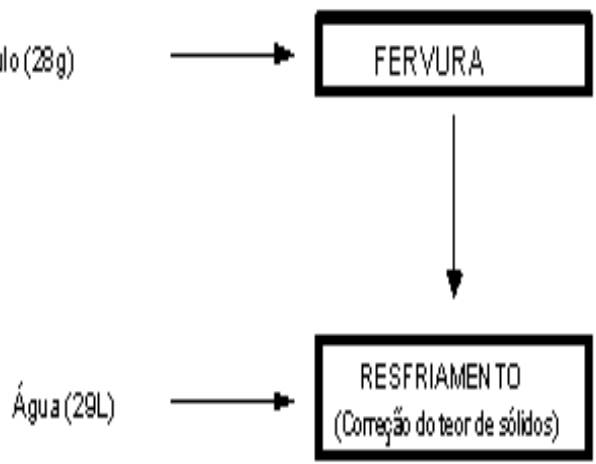
FIGURA 3 - FLUXOGRAMA DA FABRICAÇÃO DE CERVEJA UTILIZANDO FÉCULA DE BATATA COMO ADJUNTO DO MALTE E MOSTURAÇÃO PELO PROCESSO DE DUAS MASSAS

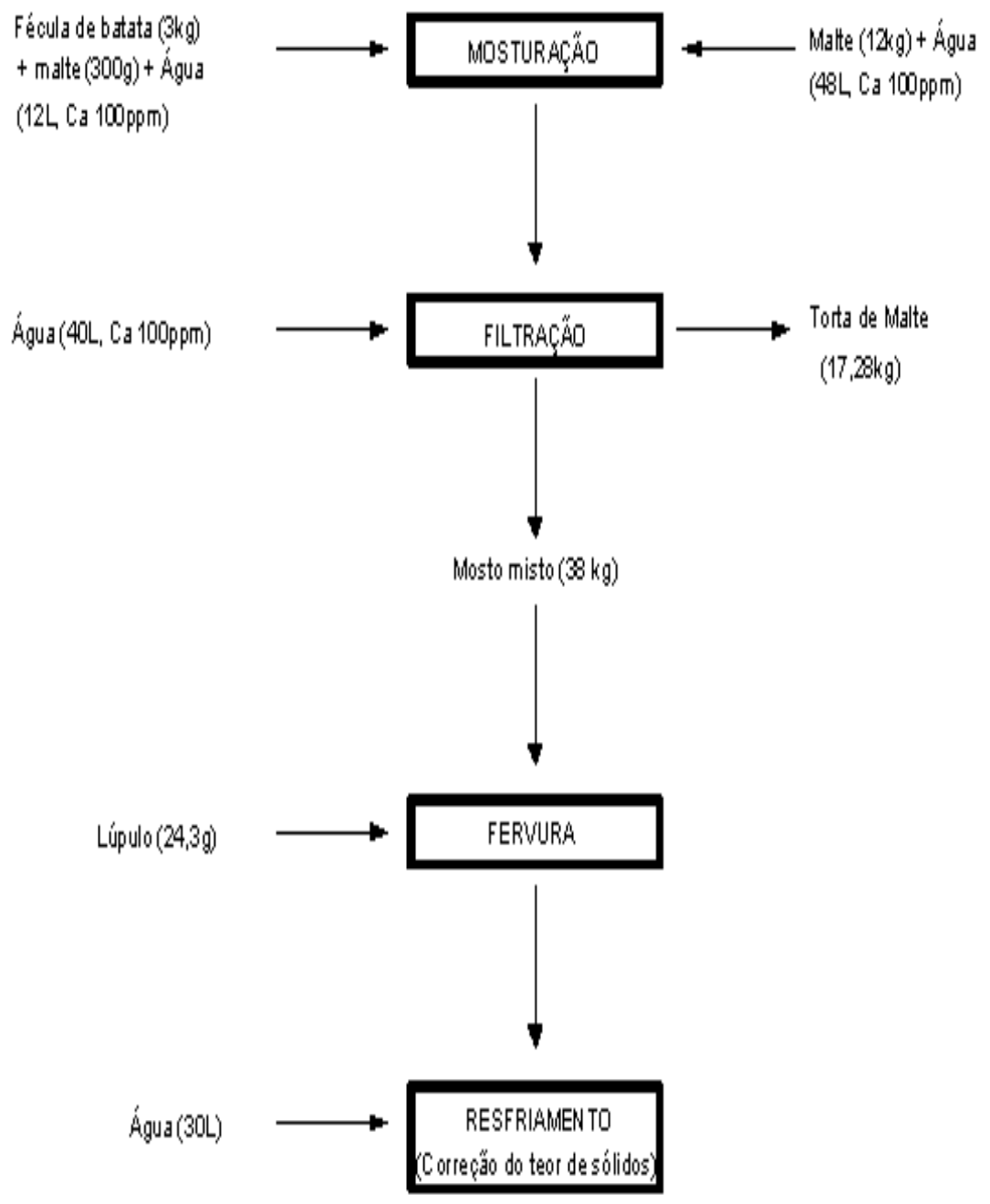




\subsubsection{Avaliação da mosturação}

Durante os processos de brassagem do mosto foram determinados os valores dos seguintes parâmetros:

a) teor de açúcares (ou extrato aparente) do mosto primário, 'Brix;

b) teor de açúcares do mosto misto, ${ }^{\circ}$ Brix;

c) teor de açúcares na torta ao final da filtração, ${ }^{\circ}$ Brix;

d) massa de açúcar do mosto misto, g;

e) massa de mosto misto, g;

f) rendimento da mosturação, \%.

O teor de açúcar no extrato foi estimado por refratometria (refratômetro Kosmos, K92, Japão; VENTURINI FILHO, 1983). A massa de mosto misto foi obtida em balança comercial (Filizola, Brasil) com capacidade para $20 \mathrm{~kg}$ e sensibilidade de $20 \mathrm{~g}$. A massa de açúcar do mosto misto foi calculada pela equação 1 .

$$
m_{a c}=\frac{\text { teor }_{a c} \times m_{\text {mosto }}}{100}
$$

na qual: $m_{a c}=$ massa de açúcar do mosto misto, $g_{1}$

$$
\begin{aligned}
& \text { teor }{ }_{a c}=\text { teor de açúcar no extrato, }{ }^{\circ} \mathrm{Brix} ; \\
& m_{\text {mosto }}=\text { massa de mosto, } \mathrm{g} .
\end{aligned}
$$

O rendimento da mosturação foi calculado pela equação 2 , segundo $D E$ CLERCK (1958).

$$
\text { Rendimento }=\frac{m_{a c}}{m_{\text {malte }}+m_{\text {adjunto }}} \times 100
$$

Na qual: $m_{a c}=$ massa de açúcar do mosto misto, $g$;

$$
\begin{gathered}
m_{\text {majte }}=\text { massa de malte, } g_{1} \\
m_{\text {aqjiuxto }}=\text { massa de adjunto, } g .
\end{gathered}
$$




\section{RESULTADOS E DISCUSSÃO}

Os dados resultantes da comparação do comportamento da fécula de batata e do amido de milho, quando utilizados como adjuntos cervejeiros no processo de mosturação de duas massas, são apresentados na Tabela 1.

TABELA 1 - DADOS EXPERIMENTAIS

\begin{tabular}{|c|c|c|}
\hline Análise & Amido de milho & Fécula de batata \\
\hline Teor de açucar do mosto primário ("Brix) & 20,9 & 10,2 \\
\hline Teor de açúcar do mosto da lavagem ("Brix) & 14,7 & 7,0 \\
\hline Teor de açúcar do mo sto misto ("Brix) & 18,0 & 8,6 \\
\hline Volume do mosto primário (L) & 22 & 23 \\
\hline Volume de filtrado (L) & 21 & 15 \\
\hline Volume de mosto misto (L) & 43 & 38 \\
\hline Massa do mosto misto $(\mathrm{kg})$ & 43 & 38 \\
\hline Massa de açúcar do mosto misto (kg) & 7,74 & 3,496 \\
\hline Teor de açúcar no filtrado ("Brix) & 9,7 & 9,0 \\
\hline Massa da torta da filtraçăa (kg) & 15,39 & 17,28 \\
\hline Rendimento da mosturaçăo (\%) & 50,6 & 22,8 \\
\hline
\end{tabular}

Observou-se maior teor de açúcar no extrato do amido de milho em relação à fécula de batata, indicando que a hidrólise foi mais eficiente no amido de milho do que na fécula. O volume do mosto proveniente do amido de milho foi maior do que o volume apresentado pela fécula. Entretanto, como foram usadas as mesmas condições para o amido de milho e para a fécula de batata a diferença entre os volumes é pequena.

Calculou-se a massa de mosto misto com base na densidade da água a $25^{\circ} \mathrm{C}$. A massa do extrato no mosto misto foi calculada pela equação 1 
e aplicada à equação 2 para a determinação do rendimento da mosturação.

Os teores de açúcar no extrato das tortas ao final da segunda filtração (após a lavagem) apresentaram valores elevados, provavelmente devido ao fato do bagaço ter sido lavado somente uma vez, havendo necessidade de outra lavagem com $40 \mathrm{~L}$ de água para retirada a do açúcar residual que tenha permanecido na torta, levando a um valor de composição ( $\left.{ }^{\circ} B r i x\right)$ próximo da unidade. A torta da fécula de batata apresentou maior massa em comparação à torta do amido da milho.

O amido de milho evidenciou maior rendimento de mosto do que a fécula de batata.

\title{
4 CONCLUSÃO
}

A hidrólise do amido de milho disponibilizou maior quantidade de açúcar solúvel para o meio comparado com a fécula de batata. Isto pode ser devido à constituição química diferenciada das duas fontes de amido em termos de amilose e amilopectina. Deve-se considerar ainda que a batata apresenta baixo teor de proteínas e óleo, o que diminui o risco de turvação, melhora a estabilidade da espuma da cerveja e reduz gastos com o uso de estabilizantes. A estabilidade física da cerveja proporciona maior tolerância ao resfriamento e maior vida de prateleira.

\begin{abstract}

\section{POTATO STARCH AS MALT ADJUNCT IN BEER PRODUCTION}

The objective of this work was to compare the beer wort yield using maize and potato starch as malt adjunct for the production of a beer with better final quality. That parameter was evaluated, mainly, in relation to production yield of sugar in the primary wort, in the mixed wort and in the filtrate. In the beer processing the mashing was done by double mash process. The maize starch hydrolysis resulted in a greater soluble sugar content yield when compared to the potato starch. This can be due to the differentiated chemical constitution of the two sources of starch in amylose terms and amylopectin. Although it should be considered that the potato contains a smaller oil and protein content, lessening the beer clouding risk, improves foam stability and reduces expenses with stabilizers. The physical stability of the beer would provide larger tolerance to cooling and larger shelf life.
\end{abstract}

KEY-WORDS: MAIZE STARCH; POTATO STARCH; MASHING; BEER. 


\section{REFERÊNCIAS}

1 AMBEV. Companhia Brasileira de Bebidas. Cervejas: fabricação e ingredientes. http://www.ambev.com.br/produtos/cervejas. Acesso: 13/ 06/2005.

2 ARAUJO, F. B. Perfil sensorial, cromatográfico e características físicoquímicas de cervejas provenientes de dois segmentos de mercado. Viçosa, MG, 2000. 109 p. Dissertação (Mestrado em Ciência e Tecnologia de Alimentos), Universidade Federal de Viçosa.

3 COSTA JÚNIOR, J. A. Desenvolvimento de um processo de produção de xarope de maltose a partir do "grits" de milho. Viçosa, MG, 1996. 68 p. Dissertação (Mestrado em Ciência e Tecnologia de Alimentos), Universidade Federal de Viçosa.

4 DE CLERK, J. A textbook of brewing. London: Chapman \& Hall, 1958. v. 1.

5 FRANCO, G. Tabela de composição química dos alimentos. São Paulo: Atheneu, 2002.

6 HORNSEY I. S. Elaboración de cerveza: microbiologia, bioquimica y tecnologia. Zaragoza: Acribia, 2002. 229 p.

7 LEE, B. H. Fundamentals of food biotechnology. New York: John Wiley Professio, 1996. 448 p.

8 LEWIS, M.J.; YOUNG, T.W. Brewing. London: Chapman \& Hall, 1995. $260 \mathrm{p}$.

9 KUIPER, S.; RIJN, C. V.; NIJDAM, W.; RASPE, O.; WOLFEREN, H. V.; KRIJNEN, G.; ELWENSPOEK, M. Filtration of lager beer with microsieves: flux, permeate haze and in-line microscope observations. Journal of Membrane Science, v. 196, n. 2, p. 159-170, 2001.

10 MULLER, R. A mathematical model of the formation of fermentable sugars from starch hydrolysis during high-temperature mashing. Enzyme and Microbial Technology, v. 27, p. 337-344, 2000.

11 NAKANO, V. M. Teoria da fermentação e maturação. In: WORKSHOP ADEGAS - AMBEV, Brasília, 2000. Anais... Brasília: AMBEV, 2000. v.1. 
12 PERPÈTE, P.; COLLIN, S. How to improve the enzymatic worty flavour reduction in a cold contact fermentation. Food Chemistry, v. 70, n. 4, p. 457-462, 2000.

13 REINOLD , M. R. Manual prático de cervejaria. São Paulo: Aden, 1997. $214 \mathrm{p}$.

14 TSCHOPE, E. C. Microcervejarias e cervejarias: a história, a arte e a tecnologia. São Paulo: Ed. Aden, 2001. 223 p.

15 VARNAM, A; SUTHERLAND, J. Bebidas: tecnología, química y microbiología. Zaragoza : Acribia, 1994. p.307-365.

16 VENTURINI FILHO, W. G. Fécula de mandioca como adjunto de malte na fabricação de cerveja. Botucatu, 1993. 233 p. Dissertação (Mestrado), Universidade Estadual "Júlio de Mesquita Filho".

17 YU, B.; ZHANG, F.; ZHENG, Y.; WANG, P. Alcohol fermentation from the mash of dried sweet potato with its dregs using immobilised yeast. Process Biochemistry, v. 31, n. 1,p. 1-6, 1996. 